\title{
Investigation of the emotional and psychological factors of elderly persons frequenting ballroom dancing clubs
}

Daniel Vicentini de Oliveira'

Priscila Facini Favero ${ }^{2}$

Renan Codonhato ${ }^{3}$

Caio Rosas Moreira ${ }^{3}$

Mateus Dias Antunes ${ }^{4}$

José Roberto Andrade do Nascimento Júnior ${ }^{5}$

Abstract

Objective: the present study investigated the psychological and emotional factors of elderly persons who practiced ballroom dancing. Method: the sample consisted of 93 elderly people who attended ballroom dancing clubs in the city of Maringá, in Paraná, Brazil. The Perceived Stress Scale, Self-Esteem Scale, Geriatric Anxiety Inventory, Life Satisfaction Scale and the SF-12 questionnaire were used. The data were analyzed using the Kolmogorov-Smirnov (data normality), Mann-Whitney U and Kruskal-Wallis tests (comparison of psychological variables according to sociodemographic and health variables), Spearman Correlation and Multivariate Linear Regression (relationship between variables). Results: there was a predominance of a good perception of health (69.9\%); adequate values of life satisfaction $(\mathrm{Md}=27.00, \mathrm{Q} 1=25.00, \mathrm{Q} 3=30.00)$ and self-esteem $(\mathrm{Md}=31.00, \mathrm{Q} 1=30.00, \mathrm{Q} 3=32.00)$; as well as physical $(\mathrm{Md}=59.40, \mathrm{Q} 1=50.00, \mathrm{Q} 3=62.50)$; and mental health perception $(\mathrm{Md}=71.90, \mathrm{Q} 1=62.50, \mathrm{Q} 3=78.12)$. Low levels of anxiety $(\mathrm{Md}=6.00, \mathrm{Q} 1=3.00, \mathrm{Q} 3=12.00)$ and depression $(\mathrm{Md}=3.00, \mathrm{Q} 1=2.00, \mathrm{Q} 3=4.00)$, and a perception of moderate levels of stress $(\mathrm{Md}=20.00, \mathrm{Q} 1=13.50, \mathrm{Q} 3=24.50)$ were also found. Elderly people with a good perception of health were more satisfied with life and had higher self-esteem and lower levels of anxiety, stress and depression than those with poor/regular perception; anxiety $(\beta=-0.32)$ and depression $(\beta=-0.15)$ had a negative impact on life satisfaction, predicting its variability by $21 \%$. Conclusion: the elderly had a healthy profile, and anxiety and depression were the main psychological and emotional factors that negatively influenced the satisfaction with life of these elderly people.

\footnotetext{
Universidade Estadual de Campinas, Faculdade de Ciências Médicas, Departamento de Pós-Graduação Stricto Sensu em Gerontologia. Campinas, SP, Brasil.

2 Faculdade Metropolitana de Maringá, Departamento de Educação física. Maringá, PR, Brasil.

3 Universidade Estadual de Maringá. Departamento de Pós-Graduação Stricto Sensu em Educação física. Maringá, PR, Brasil.

4 Centro Universitário de Maringá. Departamento de Pós-Graduação Stricto Sensu em Promoção da saúde. Maringá, PR, Brasil.

5 Universidade Federal do Vale do São Francisco. Departamento de Educação física. Petrolina, PE, Brasil.

Research funding: Instituto Cesumar de Ciência, Tecnologia e Inovação (ICETI) and the Coordenação de Aperfeiçoamento de Pessoal de Nível Superior (the Coordination for the Improvement of Higher Education Personnel) (CAPES) for the granting of research assistance grants - 01P-3372/2017.
} Correspondence

Daniel Vicentini de Oliveira

E-mail: d.vicentini@hotmail.com

Keywords: Motor Activity. Gerontology. Health Promotion. 


\section{INTRODUCTION}

The psychosocial and emotional changes that occur during aging ${ }^{1}$ include a decrease in selfesteem $^{2}$ and psychological and subjective well-being ${ }^{3}$ and an increase in anxiety ${ }^{4}$, which can lead to the development of depression and in the long term may influence decline in functional and cognitive capacity and subsequent impairment in the quality of life of this population ${ }^{5}$.

For the elderly, self-esteem is related to the admiration, appreciation and importance that is attributed to them, as well as their positive relationship with society and their family and friends ${ }^{6}$. Anxiety, meanwhile, is a factor that may be related to other comorbidities in this population. Symptoms of anxiety can predict limitations in the activities of daily living of elderly persons ${ }^{7,8}$. Moreover, anxiety in the elderly is also related to major depressive disorders?.

The subjective well-being of the individual throughout aging is an important indicator of quality of life. Experiences and adaptations that have and still occur in life, and which provide feelings of happiness, positive pleasure and affection, as well as the absence of negative affect, are essential for satisfaction with life, especially among the elderly ${ }^{10}$. An individual with low indicators of subjective well-being will also exhibit a concomitant increase in their perception of stress as a consequence of a series of factors that follow the decline in their subjective well-being. Such processes of stress can influence the emergence of diseases and difficulties in performing activities of daily living (ADLS) ${ }^{11}$. The careful observation of depressive symptoms is also of paramount importance, as such symptoms reflect both positive and negative emotions and feelings, and provide highly relevant information for the mental health care of the elderly ${ }^{12}$.

As a consequence of the aging process and the physical, psychological and emotional changes it causes, the elderly population is highly sensitive to changes in quality of life ${ }^{13}$. Quality of life, in addition to encompassing basic aspects of the overall health of the individual, is also a reflection of their understanding and position in life within their cultural context, and includes their goals, expectations, patterns, and concerns about themselves ${ }^{14}$. It is therefore emphasized that quality of life is closely linked to life habits, such as physical exercise and socialization, potential promoters of physical and mental health ${ }^{15}$.

When performing physical activity, the elderly can maintain an active level of physical, cognitive, social and psychological functioning ${ }^{16}$. Among the existing modalities of physical exercise, dancing is popular among this population, as it provides an environment of relaxation and fun, where the elderly can identify with individuals with similar cultural characteristics and interact socially with others, as well as expressing their emotions and relive feelings of the past. Dancing can therefore benefit the quality of life of these individuals, who set aside many problems, such as shyness, anxiety and depression, and therefore contributes to a better quality of life $\mathrm{e}^{17}$.

The objective of the present study was therefore to investigate the psychological factors of elderly people attending ballroom dancing clubs, aiming to clarify the relationship between these factors and their impact on life satisfaction.

\section{METHOD}

The study included 93 elderly persons of both genders who regularly performed activities in ballroom dancing clubs in the city of Maringá, Paraná, Brazil. The sample was selected in a nonprobabilistic and intentional manner for convenience. The inclusion criterion where that the elderly should have participated in their respective groups for at least three months. Elderly people with perceptible auditory and cognitive deficits, in addition to those with neurological diseases that made them incapable of carrying out the questionnaires, were excluded.

To characterize the sociodemographic and health profile of the sample, a semi-structured questionnaire developed by the authors was applied, with questions relating to gender (male and female), chronological age (the values of which were grouped into ranges of 60 to 69,70 to 79 , and 80 years and over), monthly income in 2016 (grouped into bands of up to one minimum wage, one to two minimum wages, and over two minimum wages), schooling (data grouped into categories 0 years of study, one to four years of study, up to eight years of study and more than eight 
years of study), occupational status (active or inactive), race (white, black, Asian-Brazilian), retirement (yes or no), smoking (never smoked, smoked or currently smoked); time frequented ballroom dancing club (up to 5 years, more than 5 years), weekly attendance at ballroom dancing clubs (twice a week, 3 times a week, 4 times or more) and history of falls in the last six months (yes or no).

To evaluate stress levels, the Perceived Stress Scale ${ }^{18}$, which consists of 14 questions about the feelings and thoughts of the elderly persons over the previous month, was used. This instrument is answered on a five-point Likert scale (zero $=$ never, one $=$ almost never, two $=$ sometimes, three $=$ almost always, and four = always). Questions 4, 5, 6, 7, $9,10,13$ are positive in relation to the individual, and are thus scored in an inverted manner. The other questions, with a negative character, have an immediate summation. The final score is a result of the sum of the scores of the 14 questions, ranging from 0 to 56 points, with a higher score indicating a greater perception of stress.

The Geriatric Anxiety Inventory, validated for the Brazilian context by Martiny et al. ${ }^{19}$, was applied to evaluate the anxiety levels of the sample group. This instrument consists of 20 questions, answered yes or no, with each yes answer adding one point to the final score of the individual. Scores equal to or greater than ten identify the elderly person as suspected of suffering from generalized anxiety.

In order to identify depressive symptoms, the Geriatric Depression Scale ${ }^{20}$, which consists of 15 dichotomous items, was used. Scores greater than five indicate depression.

To evaluate self-esteem, the Rosenberg SelfEsteem Scale, validated for Brazil by Hutz and Zanon $^{21}$, was used. This instrument consists of ten questions, answered on a four-point Likert scale ranging from 1 (totally disagree) to 4 (totally agree). The final result is obtained from the sum of the scores of the questions, ranging from 10 to 40 points. Higher values indicate greater self-esteem.

Subjective well-being was evaluated through the Satisfaction with Life Scale, validated for Brazil ${ }^{22}$. This scale is one-dimensional in nature and is composed of five questions answered on a scale of 07 points. The higher the value, the greater the satisfaction with life and vice versa.

Quality of life was assessed using the ShortForm Health questionnaire (SF12v2) in its validated Portuguese version $^{23}$. This instrument assesses the individual's perception of their own physical and mental health through 12 questions answered on a Likert-type scale of five points (with the exception of question 02 , which is answered via a three point scale). From the answers, the general scores of Total Quality of Life, Physical Health and Mental Health can be calculated, as well as the specific dimensions of functional capacity, limitation by physical aspects, pain, general health, vitality, social aspects and emotional aspects. For the present study, the general dimensions of results were used.

The survey was conducted from November 2016 to March 2017. Initially, contact was made with the managers of ballroom dancing clubs in the municipality of Maringá, Paraná. After the necessary clarifications, and the authorization of such managers, the collection of data began at the clubs at pre-scheduled times. The elderly persons were approached by the researcher responsible, who explained the objectives and nature of the research. The elderly who voluntarily agreed to participate in the study signed a Free and Informed Consent Form (FICF).

The interviews were individual and used only pencil and paper. They were performed by the researchers and lasted from 10 to 25 minutes per elderly person.

For the analysis of the categorical variables, the descriptive frequency and percentage statistics were used. For the numerical variables, the normality of the data was verified through the Kolmogorov-Smirnov test. As the data did not present normal distribution, Median (Md) and Quartiles (Q1;Q3) were used as descriptive measures. For the comparison of the psychological and emotional variables according to gender, monthly income and health perception, the Mann-Whitney U test was used. To compare the psychological and emotional variables according to the age group, the Kruskal-Wallis test followed by the Mann-Whitney U test was used to evaluate the pairs 
of groups. In order to verify the correlations between the study variables, the Spearman Correlation Coefficient $(\mathrm{p}<0.05)$ was applied.

A Multivariate Linear Regression model was then constructed using the variables which had a significant correlation with satisfaction with life as predictors. The existence of outliers was evaluated by the squared Mahalanobis distance $\left(\mathrm{D}^{2}\right)$ and the univariate normality of the variables was evaluated by the uni- and multivariate coefficients of asymmetry $(\mathrm{IS} k \mathrm{I}<3)$ and kurtosis $(\mathrm{I} K u \mathrm{I}<10)$. As the data did not present normal distribution, the Bollen-Stine Bootstrap technique was used to correct the value of the coefficients estimated by the Maximum Likelihood method implemented in the AMOS software package version 18.0. There were no $D M^{2}$ values indicating the existence of outliers, nor sufficiently strong correlations among variables to indicate problems with multicollinearity (Variance Inflation Factors $<5.0$ ). The regression coefficients were based on the following coefficients: low effect for coefficients $<0.20$, medium effect for coefficients up to 0.49 and strong effect for coefficients $>0.50$ $(p<0.05)$. The present study was approved by the Ethics Research Committee of the Centro Universitário de Maringá, under approval number 2.091.893/2017, CAAE 67067517.6.0000.5539.

\section{RESULTS}

In the present study, the sample consisted of 93 elderly persons, with 19 men and 74 women $(79.6 \%)$, a mean age of $70.4( \pm 7.1)$, aged between 60 and 69 years $(53.8 \%)$, unmarried (single, widowed, divorced and separated $(92.5 \%)$, white $(66.7 \%)$, retired $(83.7 \%)$, with a monthly income of one to two minimum wages $(84.9 \%)$ and inactive $(82.8 \%)$. The majority of the elderly had an incomplete primary education $(52.7 \%)$ and $9.7 \%$ had no formal schooling ( 0 years of study). The majority $(71.0 \%)$ had attended ballroom dancing groups for at least five years and at least twice a week $(58.1 \%)$. The majority of the elderly were perceived to be in good health $(69.9 \%)$, and had no history of falls in the last six months $(86.0 \%)$.

Regarding psychological and emotional aspects, it was found that the majority of the elderly persons were not suspected of suffering from anxiety $(64.5 \%)$ or depression $(84.9 \%)$. Figure 1 shows that the elderly had moderate to high levels of Life Satisfaction $(\mathrm{Md}=27.0)$ and Self-Esteem $(\mathrm{Md}=31.0)$; low levels of Anxiety $(\mathrm{Md}=6.0)$, moderate levels of perceived stress $(\mathrm{Md}=20.0)$ and low signs of depression $(\mathrm{Md}=3.0)$. Moderate values were found for perception of physical $(\mathrm{Md}=59.4)$ and there were high perceptions of mental health perception ( $\mathrm{Md}=71.9)$.

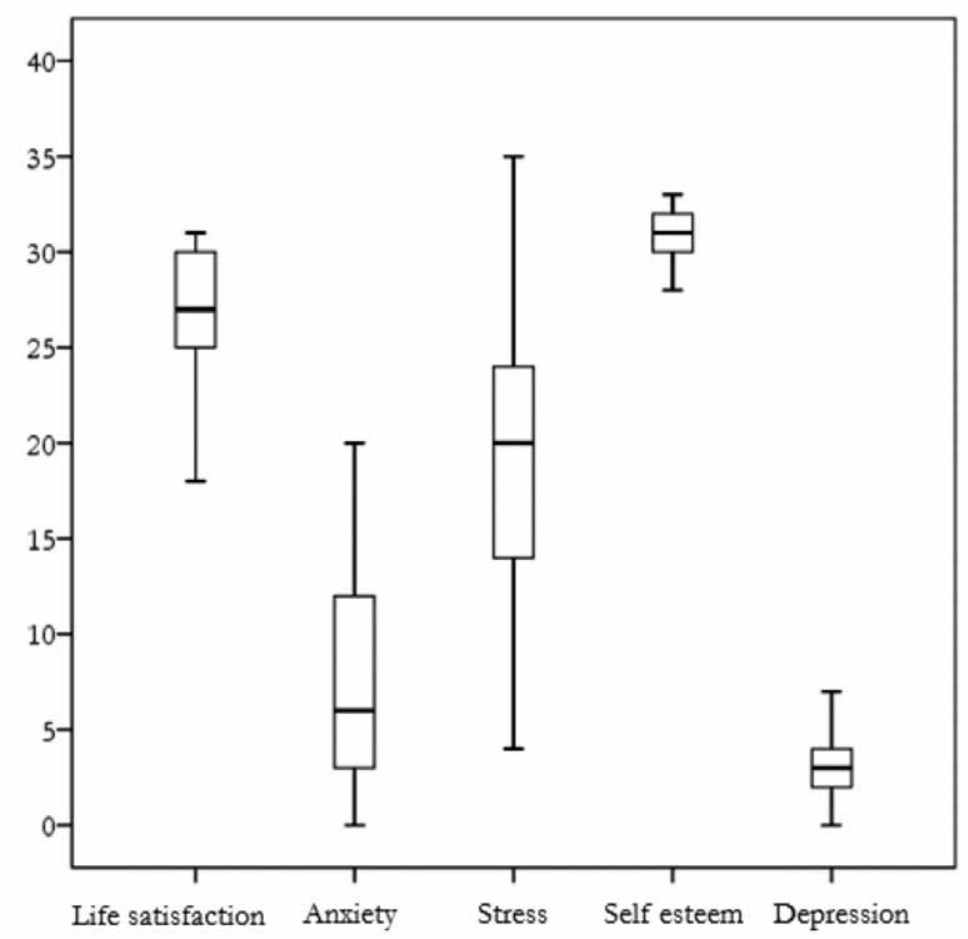

Figure 1. Psychological profile of elderly people attending ballroom dance clubs Maringá, Paraná, 2017. 
When comparing the psychological variables of the elderly attending ballroom dancing clubs based on gender, age group and monthly income, no significant differences were found ( $p>0.05)$. In comparisons based on perception of health (Table $1)$, there was a significant difference $(p<0.05)$ in all the variables except for quality of life. Higher life satisfaction, better self-esteem and lower levels of anxiety and stress characterized elderly persons with a good perception of health, while those with a poor/ fair perception of health exhibited more anxiety and stress and profiles that were more indicative of depression, as well as lower self-esteem and satisfaction with life.
When correlating the psychological and emotional variables (Table 2), it was found that life satisfaction was negatively related to anxiety $(\mathrm{r}=-0.41)$, stress $(\mathrm{r}=-0.30)$ and being indicative of depression $(\mathrm{r}=$ $0.30)$, and positively related to self-esteem $(\mathrm{r}=0.21)$. In addition, it was observed that self-esteem was inversely related to negative psychological factors (anxiety, being indicative of depression and stress), whereas these correlated positively among each other.

A multivariate regression model was constructed to verify the impact of the psychological variables measured on the life satisfaction of the elderly people (Figure 2).

Table 1. Comparison of the psychological variables of elderly people attending ballroom dancing clubs based on self-perception of health. Maringá, Paraná, 2017.

\begin{tabular}{|c|c|c|c|}
\hline \multirow{3}{*}{ Variables } & \multicolumn{2}{|c|}{ Perception of health } & \multirow{3}{*}{$P$} \\
\hline & Good & Poor/Fair & \\
\hline & Md (Q1;Q3) & Md (Q1;Q3) & \\
\hline Life satisfaction & $28.0(26.0 ; 30.0)$ & $26.0(21.3 ; 28.0)$ & $0.009 *$ \\
\hline Anxiety & $5.0(2.5 ; 10.0)$ & $11.0(5.3 ; 15.0)$ & $0.002^{*}$ \\
\hline Stress & $18.0(12.0 ; 24.0)$ & $24.0(18.0 ; 26.0)$ & $0.013 *$ \\
\hline Self-esteem & $31.0(30.0 ; 32.0)$ & $30.5(29.3 ; 31.0)$ & $0.012^{*}$ \\
\hline Indicative of Depression & $3.0(1.0 ; 3.0)$ & $4.0(3.0 ; 4.8)$ & $0.001 *$ \\
\hline \multicolumn{4}{|l|}{ Quality of life } \\
\hline Physical health & $59.4(50.0 ; 62.5)$ & $57.8(50.8 ; 62.5)$ & 0.806 \\
\hline Mental Health & $71.9(62.5 ; 75.0)$ & $71.9(62.5 ; 78.1)$ & 0.303 \\
\hline Overall QoL & $62.5(58.6 ; 67.9)$ & $66.4(59.3 ; 68.7)$ & 0.349 \\
\hline
\end{tabular}

*Significant difference: $p<0.05$-Mann-Whitney U-test; QoL: quality of life; Md: median; Q1/Q3: quartiles.

Table 2. Correlation between the psychological and emotional variables of elderly people attending ballroom dancing clubs. Maringá, Paraná, 2017.

\begin{tabular}{|c|c|c|c|c|c|c|c|c|}
\hline Variables & 1 & 2 & 3 & 4 & 5 & 6 & 7 & 8 \\
\hline 1. Life satisfaction & & $-0.41 *$ & $-0.30 *$ & $0.21 *$ & $-0.30 *$ & 0.06 & 0.07 & 0.07 \\
\hline 2. Anxiety & & & $0.59 *$ & $-0.37 *$ & $0.42 *$ & -0.03 & -0.20 & -0.19 \\
\hline 3. Stress & & & & $-0.39 *$ & $0.40 *$ & -0.18 & -0.15 & -0.18 \\
\hline 4. Self-esteem & & & & & $-0.37 *$ & 0.06 & -0.03 & 0.06 \\
\hline 5. Indicative of Depression & & & & & & -0.08 & -0.02 & -0.03 \\
\hline 6. QoL in Physical Health & & & & & & & $0.23 *$ & $0.73 *$ \\
\hline 7. QoL in Mental Health & & & & & & & & $0.80 *$ \\
\hline 8. Total QoL & & & & & & & & \\
\hline
\end{tabular}

*Significant correlation (Spearman Correlation) $p<0.05$; QoL: quality of life. 


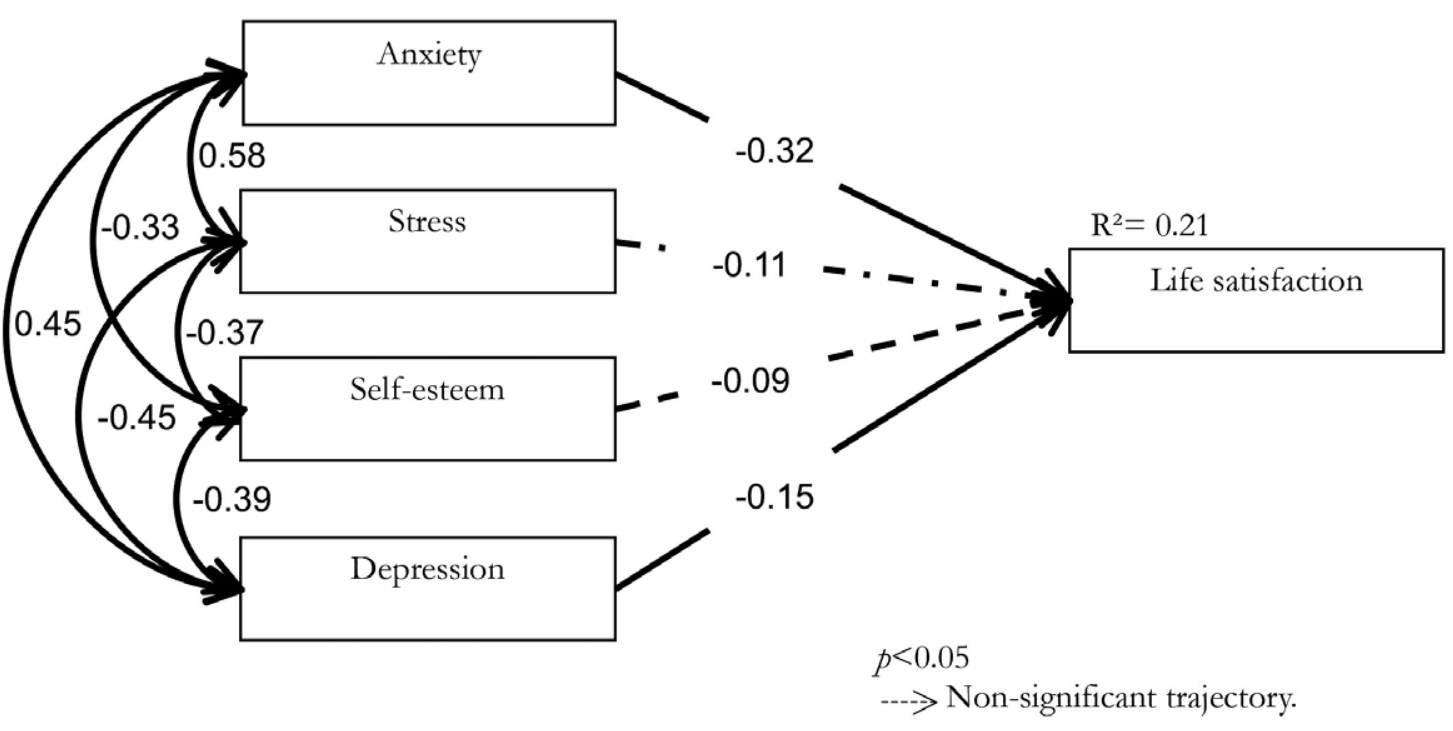

Figure 2. Impact of psychological and emotional variables on the life satisfaction of elderly ballroom dancing club members. Maringá, Paraná, 2017.

It is observed that anxiety, stress, self-esteem and depression predicted $21 \%$ of the variability of the life satisfaction of these elderly people (Figure 2). Regarding the individual trajectories of the model, it was verified that only anxiety $(\beta=-0.32)$ and depression $(\beta=-0.15)$ had a significant impact on life satisfaction. It is noteworthy that the increase of one standard deviation in the anxiety and depression units causes a reduction of 0.32 and 0.15 standard deviations, respectively, in the life satisfaction unit. Stress and self-esteem did not exhibit significant regression coefficients $(p>0.05)$.

\section{DISCUSSION}

The present study sought to investigate the emotional and psychological factors of elderly people attending ballroom dancing clubs. It was observed that the majority of these elderly persons exhibited indicators of a profile of satisfactory quality of life, as they perceived themselves to have good general health, had good levels of self-esteem and life satisfaction and a good perception of physical and mental health, as well as low anxiety, stress and few indicators of depression. It can be inferred that the individuals evaluated in this sample of elderly persons who attended ballroom dancing clubs have a relatively high emotional and psychological profile, reinforcing the importance of physical activities for this population.
There was a predominance of desirable aspects of quality of life and health, which suggests a distancing from the problems typically faced by this population, such as social isolation, depression and accidents (falls). Such results may or may not be linked to the regular practice of ballroom dancing, which develops important physical abilities for the prevention falls and increases the autonomy of the elderly in activities of daily living, in addition to providing an environment rich in social interactions ${ }^{25}$. It was observed that most of the sample attended ballroom dancing clubs for more than five years, with the hypothesis that frequency in attending such groups may have been an influence factor for the profile found in the sample.

Sedentary behavior in the elderly population has been related to cognitive deficits, which may in turn impair the well-being and quality of life of such individuals, while physical exercise plays an important role in mitigating or even protecting against such deleterious effects of aging ${ }^{26,27}$. Evidence shows that sedentary elderly persons have a worse quality of life than active individuals ${ }^{28}$.

There is a consensus about the benefits of performing physical activities and exercises among the elderly population. It has been found that physical exercises are potential promoters of the performance and well-being of the elderly, from sedentary individuals to elite athletes ${ }^{15}$. A systematic review ${ }^{16,18}$ 
evaluated controlled and randomized clinical trials investigating the self-esteem, symptoms of depression and the quality of life of the elderly aged over 65 and concluded that exercise programs for this group effectively improve such variables.

On the other hand, there is also evidence that physical exercise is not directly related to improvements in the psychological well-being of the elderly ${ }^{29}$, although an analysis of literature suggests that such divergence may be related to the type of physical activity practiced. It is observed that, when dealing specifically with dancing, there is a consensus regarding the favorable results for the emotional and psychological health of the elderly. Studies conducted in Hong Kong ${ }^{30}$, Greece ${ }^{31}$ and Turkey ${ }^{25}$ have shown the effectiveness of dance in reducing levels of stress and anxiety, improved the subjective perception of quality of life and well-being, and produced physical benefits favorable to the autonomy of the elderly.

Regarding the impact of psychological and emotional factors on life satisfaction as evaluated by the regression model, it was observed that, for this sample, anxiety levels and symptoms of depression appear to be intervening factors in the satisfaction of the elderly persons with their lives. Curiously, self-esteem and stress did not present significant trajectories, despite their significance in the correlation test. However, no studies were found that evaluated the direct relationships between these variables, making it impossible to discuss their effect further. What is known is that despite the individual contribution of each variable, literature seems to agree that the practice of physical activities will bring generalized benefits to the quality of life, life satisfaction and general well-being of the elderly.

The physical activity of ballroom dancing is a potential promoter of this profile, exposing its practitioners to a context rich in social interactions and positive experiences, as well as benefiting aspects of physical health that promote the quality of life of these individuals and being an attractive environment for practitioners that motivates them to remain engaged in this long-term activity.

Thus, professionals working with the elderly should seek to develop and/ or encourage more frequent attendance of facilities that offer ballroom dancing sessions and other physical exercises, as a form of promoting the physical and mental health of the elderly.

It is important to mention the size and geographical restrictions of the sample of the present study which do not allow the generalization of the results obtained for the wider Brazilian elderly population.

\section{CONCLUSION}

The elderly participants of the ballroom dancing clubs that participated in the present study presented a psychological and emotional profile that was favorable to their well-being, life satisfaction and quality of life. Anxiety and depression can be considered detrimental variables to the life satisfaction of the elderly person.

\section{REFERENCES}

1. Guimarães ACA, Pedrini A, Matte DL, Monte FG, Parcias SR. Ansiedade e parâmetros funcionais respiratórios de idosos praticantes de dança. Fisioter Mov. 2011;24(4):683-8.

2. Tavares DMS, Matias TGC, Ferreira PCS, Pegorari MS, Nascimento JS, Paiva MM. Qualidade de vida e autoestima de idosos na comunidade. Ciênc Saúde Coletiva. 2016;21(11):3557-64.

3. Mayordomo T, Sales A, Satorres E, Melendez J. Bienestar psicológico en función de la etapa de vida, el sexo y su interacción. Pensam Psicol. 2016;14(2):101-12.
4. Casemiro FG, Rodrigues IA, Dias JC, Alves LCS, Inouye K, Gratão ACM. Impact of cognitive stimulation on depression, anxiety, cognition and functional capacity among adults and elderly participants of an open university for senior citizens. Rev Bras Geriatr Gerontol. 2016;19(4):683-94.

5. Gullich I, Duro SMS, Cesar JA. Depressão entre idosos: um estudo de base populacional no Sul do Brasil. Rev Bras Epidemiol. 2016;19(4):691-701.

6. Meurer ST, Borges LJ, Benedetti TRB, Mazo GZ. Associação entre sintomas depressivos, motivação e autoestima de idosos praticantes de exercícios físicos. Rev Bras Ciênc Esporte. 2012;34(3):683-95. 
7. Brenes GA, Guralnik JM, Williamson JD, Fried LP, Simpson C, Simonsick EM, et al. The influence of anxiety on the progression of disability. J Am Geriatr Soc. 2005;53(1):34-9.

8. Tinetti ME, Inouye SK, Gill TM, Doucette JT. Shared risk factors for falls, incontinence, and functional dependence. Unifying the approach to geriatrics syndromes. J Am Med Assoc. 1995;273(17):1348-53.

9. Cairney J, Corna LM, Veldhuizen S, Herrmann N, Streiner DL. Comorbid depression and anxiety in later life: patterns of association, subjective well-being, and impairment. Am J Geriatr Psychiatr. 2008;16(3):201-8.

10. Woyciekoski C, Stenert F, Hutz CS. Determinantes do bem-estar subjetivo. Psico. 2012;43(3):280-88.

11. De Andréa F, Lanuez FV, Machado NA, Jacob Filho W. A atividade física e o enfrentamento do estresse em idosos. Einstein. 2010;8(4):419-22.

12. Alvarenga MRM, Oliveira MAC, Facceda O. Sintomas depressivos em idosos: análise dos itens da Escala de Depressão Geriátrica. Acta Paulista Enferm. 2012;25(4):497-503.

13. Freitas CV, Sarges ESNF, Moreira KECS, Carneiro SR. Avaliação da fragilidade, capacidade funcional, e qualidade de vida dos idosos atendidos no ambulatório de geriatria de um hospital universitário. Rev Bras Geriatr Gerontol. 2016;19(1):119-28.

14. Bakas T, McLennon SM, Carpenter JS, Buelow JM, Otte JL, Hanna KM, et al. Systematic review of health-related quality of life models. Health Qual Life Outcomes. 2012;10:134-6.

15. Concannon LG, Grierson MJ, Harrast MA. Exercise in the older adult: from the sedentary elderly to the masters athlete. PM\&R. 2012;4(11):833-9.

16. Park SH, Han KS, Kang CB. Effects of exercise programs on depressive symptoms, quality of life and self-esteem in older people: a systematic review of randomized controlled trials. Appl Nurs Res. 2014;27(4):219-26.

17. De Souza MF, Marques JP, Vieira AF, Santos DC, Cruz AE, Borragine SOF. Contribuições da dança para a qualidade de vida de mulheres idosas. Rev Digit. 2010;15(148):1-10.

18. Luft CDB, Sanches SO, Mazo GZ, Andrade A. Versão brasileira da Escala de Estresse Percebido: tradução e validação para idosos. Rev Saúde Pública. 2007;41(4):606-15.

Recebido: 21/06/2017

Revisado: 22/09/2017

Aprovado: 04/12/2017
19. Martiny C, Silva ACO, Nardi AE, Pachana NA. Tradução e adaptação transcultural da versão brasileira do Inventário de Ansiedade Geriátrica (GAI. Rev Psiquiatr Clínica. 2011;38(1):8-12.

20. Almeida OP, Almeida SA. Confiabilidade da versão brasileira da Escala de Depressão em Geriatria (GDS) versão reduzida. Arquivos de Neuropsiquiatria. 1999;57(2B):421-6.

21. Hutz CS, Zanon C. Revisão da adaptação, validação e normatização da escala de autoestima de Rosenberg. Aval Psicol. 2011;10(1):41-9.

22. Gouveia VV, Chaves SDS, Oliveira ID, Dias MR, Gouveia RS, Andrade PD. A utilização do QSG-12 na população geral: estudo de sua validade de construto. Psicol Teoria Pesqui. 2003;19(3):241-8.

23. Damásio BF, Andrade TF, Koller SH. Psychometric Properties of the Brazilian 12-Item Short-Form Health Survey Version 2 (SF-12v2). Paidéia. 2015;25(60):29-37.

24. Kline RB. Principles and Practice of Structural Equation Modeling. New York: Guilford Press; 2012.

25. Eyigor S, Karopolat H, Durmaz B, Ibisoglu U, Cakir S. A randomized controlled trial of Turkish folklore dance on the physical performance, balance, depression and quality of life in older women. Arch Gerontol Geriatr. 2009;48(1):84-8.

26. Steinberg SI, Sammel MD, Harel BT, Schembri A, Policastro C, Bogner HR, et al. Exercisem sedentary pastimes, and cognitive performance in healthy older adults. Am J Alzheimers Dis Other Demen. 2015;30(3):290-8.

27. Edwards MK, Loprinzi PD. The association between sedentary behavior and cognitive function among older adults may be attenuated with adequate physical activity. J Phys Act Heath. 2017;14(1):52-8.

28. Fortuño-Godes J, Guerra-Balic M, Cabedo-Sanromà J. Health-related quality of life measures for physically active elderly in community exercise programs in Catalonia: comparative analysis with sedentary people. Curr Geront Geriatr Res. 2013;2013:1-6.

29. Withall J, Stathi A, Davis M, Coulson J, Thompson JL, Fox KR. Objective indicators of physical activity and sedentary time and associations with subjective well-being in adults aged 70 and over. Int J Environ Res Public Health. 2014;11(1):643-56.

30. Hui E, Chui BT, Woo J. Effects of dance on physical and psychological well-being in older persons. Arch Gerontol Geriatr. 2009;49(1):45-50.

31. Mavrovouniotis FH, Argiriadou EA, Papaioannou CS. Greek traditional dances and quality of old people's life. J Bodyw Mov Ther. 2010;14(3):209-18. 